\title{
Analysis of Current Signals in a Partially Demagnetized Vector Controlled Interior Permanent Magnet Generator
}

Research Article

\author{
Roberto Eduardo Quintal-Palomo \\ Department of Mechatronics, Faculty of Engineering, Universidad Autónoma de Yucatán \\ Av. Industrias no Contaminantes por Periférico Norte Mérida, Yucatán, México
}

Received April 29, 2019; Accepted July 09, 2019

Abstract: This manuscript analyzes the operation of an interior permanent magnet (IPM) machine working as a permanent magnet synchronous generator (PMSG). The partial demagnetization operation is analyzed. To obtain more accurate voltages and currents of the machine, finite element analysis (FEA) is used in co-simulation with the full converter and the converter's control algorithm. Direct field oriented control (DFOC) shows robustness by maintaining the speed even with a $25 \%$ demagnetized PMSG. Also, an analysis of the rotating reference frame DQ signals is done to asses demagnetization.

Keywords: IPM • PMSG • co-simulation $•$ DFOC $・$ demagnetization

\section{Introduction}

During the last two decades, advancements in material science made use of permanent magnets with high energy density $\left(\mathrm{BH}_{\max }\right)$ more pervasive. Permanent magnet synchronous machines (PMSM) have also gained popularity due to their high efficiency and high-power density, namely, low weight and volume to produce the same torque than the induction motor (IM) or wound rotor synchronous machine (WRSM). Nowadays, the highest commercially available $\mathrm{BH}_{\max }$ magnets are the neodymium-iron-boron ( $\mathrm{Nd}-\mathrm{Fe}-\mathrm{B}$ ) rare earths sintered magnets. Despite its advantages in efficiency and density, Nd-Fe-B also has its drawbacks, e.g., the magnet's price and the Nd-Fe-B dependency on temperature (Gieras, 2009). This last disadvantage means that the magnets can be demagnetized when operating at high temperatures due to the proximity of the demagnetization $(B-H)$ curve's knee at high temperatures as shown in Fig. 1.

In the literature, some experimental analysis and detection of the demagnetization conditions have been done by breaking or cutting out parts of the original magnets of the machine as shown in (Le Roux et al. 2007) with a surface permanent magnet (SPM) machine. Also in (Yang et al. 2014), the authors analyzed the partial demagnetization and inter-turn short circuit faults experimentally by intentionally breaking a piece of the SPM and analyzing the vibration signal (accelerometer) spectrum; in (Wang et al. 2016), the authors analyzed the partial demagnetization of an SPM machine through advanced signal processing (Vold-Kalman tracking filter) of current signal measurements. For the IPM machine, more recent literature also shows the detection and analysis through current measurements in an experimental setup; in (Hong et al. 2012), the authors analyzed the change of the inductance in the rotating reference frame due to demagnetization. In (Moon et al. 2017), the authors analyzed the current measurements to asses partial demagnetization and inter-turn short circuit faults. Finally, in (Park et al. 2019), the authors analyzed the partial demagnetization experimentally with a hall sensor installed close to the rotor's magnet position. 


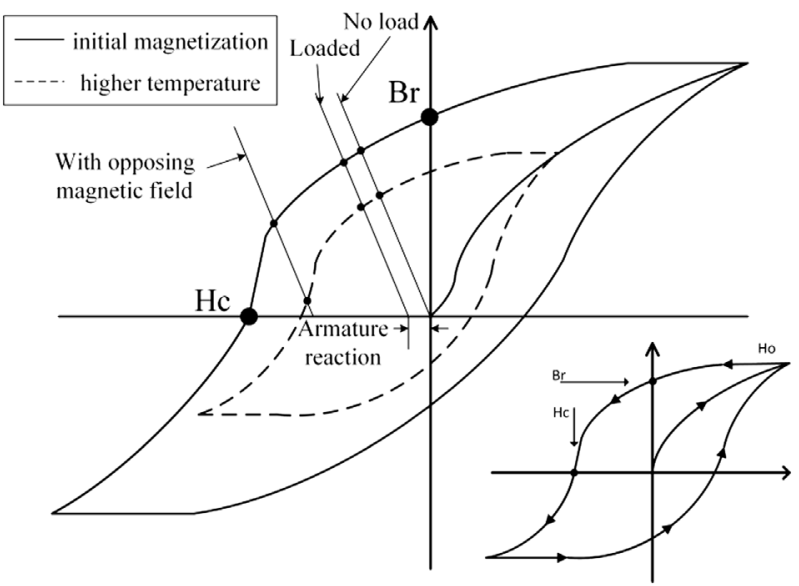

Fig. 1. Hysteresis loop for a Nd-Fe-B magnet showing the initial remanence $(\mathrm{Br})$ and coercivity $(\mathrm{Hc})$

Previous works have analyzed this effect over the permanent magnets through the FEA, e.g., in (Kang et al. 2000) and in (Rosu et al. 2005) due to the difficulties of trying to model analytically the magnetic flux density $B$ over the machine geometry, namely stator and rotor stack (laminations, slot shape), airgap, and coils. The FEA approach provides the advantage of accurately modelling all the machine geometry and the material's nonlinear characteristics. Normally, the FEA software includes an approximation of the $B-H$ curve (e.g., linear, polynomial, or exponential) as it was analysed in (Ruoho et al. 2007), but it was not until lately ( 2013) that the commercial FEA software included a temperature-dependent model as shown in (Zhou et al. 2012), this means that even with only one $B-H$ curve as input to the model, the FEA software is capable of calculating the corresponding curve based on the magnet's temperature.

About the analysis of the electrical signals for demagnetization detection, it can be found that in (Ruiz et al. 2010), the authors used the stator currents with the empirical mode decomposition (EMD) and the Hilbert-Huang Transform (HHT) to analyze the status of the demagnetization in the machine under nonstationary conditions. In (Yang 2013), they propose the Teager-Huang Transform (THT) with the energy operator decomposition (EOD) as a superior alternative to HHT. And lately, (Wang et al. 2016) proposed a Vold-Kalman filter to track harmonics connected with demagnetization even through nonstationary conditions. Most of the previous authors criticize the classical methods, e.g., fast Fourier transform (FFT) because their dependency on stationary conditions, although all of them depend on the ab initio identification of the frequencies related to certain faults, e.g., for demagnetization the work done in (Le Roux et al. 2003).

\subsection{Analysis method}

In this manuscript, an analysis of the partially demagnetized IPM is presented for four cases (healthy and three different fault locations). As mentioned above, the approach used in this research is the time stepping FEA with circuit-field coupling also named as co-simulation in the literature (Zhou et al., 2006). This method allows to analyze the partial demagnetization from the machine currents, i.e., machine current signature analysis (MCSA) as in (Ruiz et al. 2010) and also from the converter signals (e.g., DQ signals in rotating reference frame).

In Section 3, an analysis of the co-simulation results is shown and compared with the reported results in the literature.

\section{Co-simulation}

A PMSG was designed and built on the basis of a well-studied $1.5 \mathrm{~kW}$ IM, the Sh90-L4 (Baranski et al., 2017; Fei et al., 2009; Pramanik et al., 2014; Zawilak et al., 2006). This three-phase IM had the rotor removed and changed for a new design IPM rotor. In Fig. $2 a$, the geometric outline along with the magnetic field strength $H$ of the PMSG is shown. Notice that since the poles are asymmetrical, the FEA model cannot be simplified to a fraction of the machine, i.e., the machine is modelled as a whole. The details of the construction can be found in Quintal-Palomo et al. (2017). 
Notice the arrangement of the eight magnets to form a four pole machine, two of the poles are created by the other side of the magnet (opposite pole) creating what was called in the literature: induced pole (Pramanik et al., 2014).

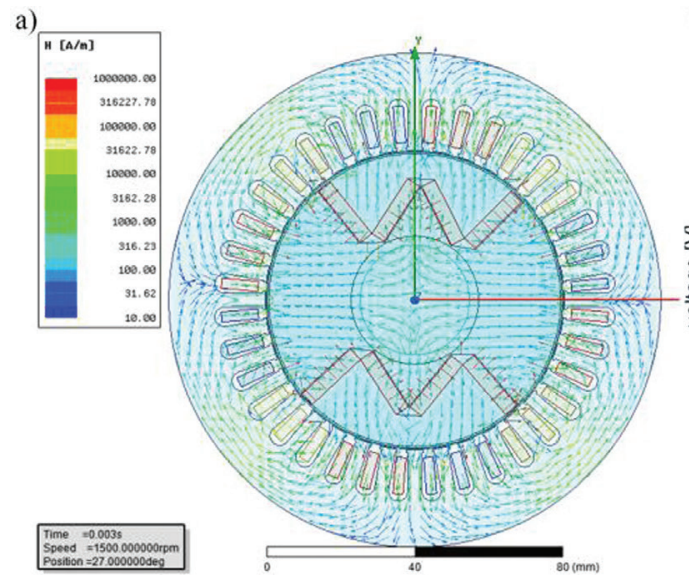

b)

Fig. 2. Magnetic field strength $H$ distribution through the PMSG in open circuit (a) line voltage in open circuit solid line are measurements, dotted line FEA results (b)

\subsection{Full converter with field oriented control}

The PMSG is operated with an active rectifier namely a two-level converter with DFOC. This is a popular control strategy for PMSGs (e.g., in wind turbines) because it allows the machine to operate at higher efficiency and in a wider speed range as analysed in (Whaley et al. 2005). In Fig. 3, a schematic diagram of the test setup is shown. Notice the importance of the speed and position feedback for the speed control and the Park transformations, respectively.

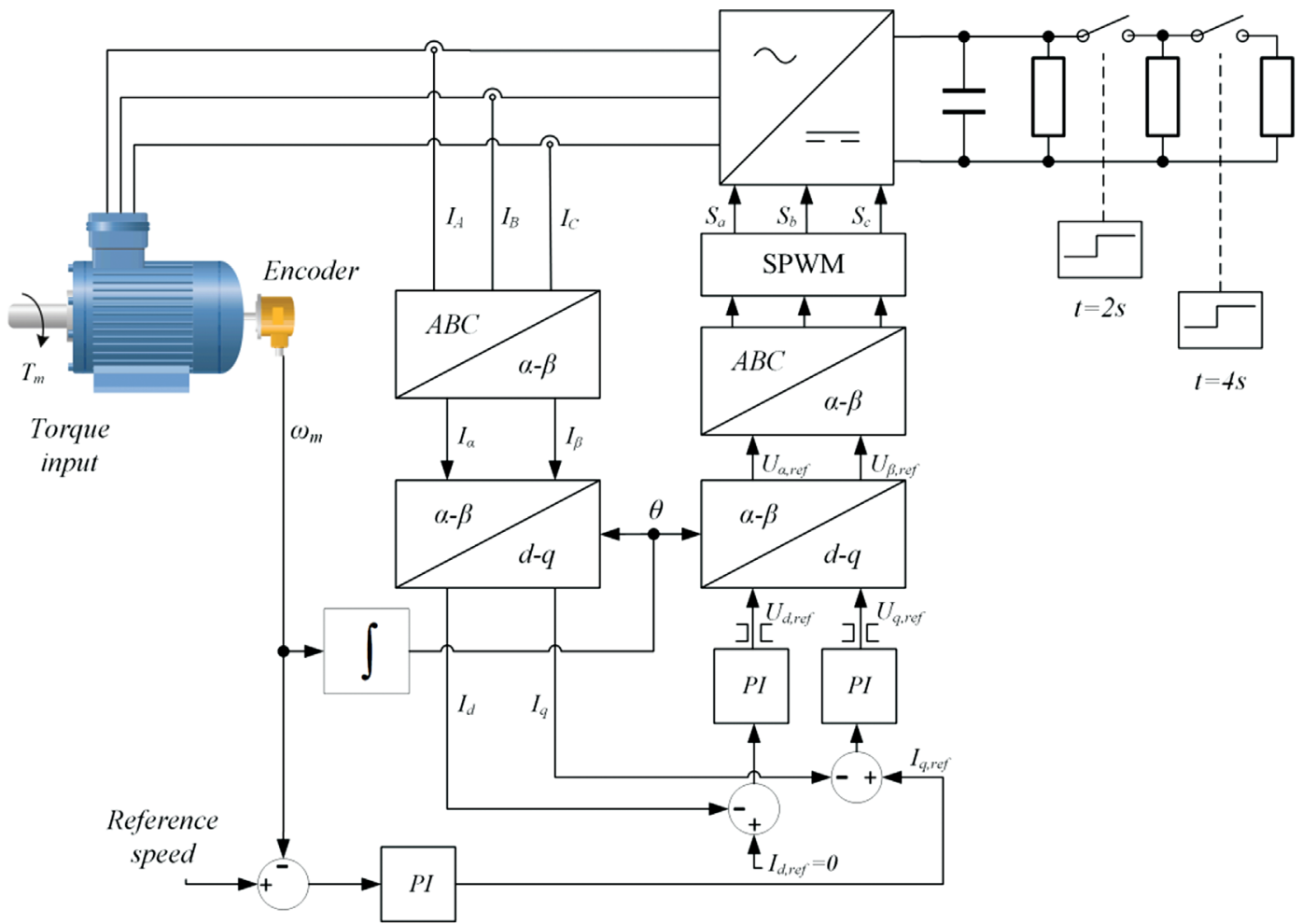

Fig. 3. Schematic diagram of the PMSG with DFOC for reference speed and load changes 
Notice in Fig. 3, that the DC bus initially has a fixed resistor $(1 \mathrm{k} \Omega)$ and after 2 seconds another resistor $(1 \mathrm{k} \Omega)$ is connected in parallel with the first and finally after another 2 seconds (4 seconds from the beginning) a third resistor (also $1 \mathrm{k} \Omega$ ) is connected in parallel with the previous two. This is done to test the control algorithm maintaining the reference speed under a load change. It is important to mention that the main purpose of the control algorithm is to maintain the reference speed in spite of changes in the load and in the input torque.

In Fig. 4, the schematic of the co-simulation setup is presented; notice that in this approach, three different specialized programs share information at each time step. In this research, the 2D FEA software (ANSYS Maxwell) has the complete geometry of the PMSG with its material properties, the multidomain, mixed-signal simulator is the ANSYS Simplorer, which is the coordinator between software and solves the power electronics circuit at each time step; finally, the control algorithm is simulated in a numerical computing environment with visual programming very popular for the control design (Matlab Simulink).

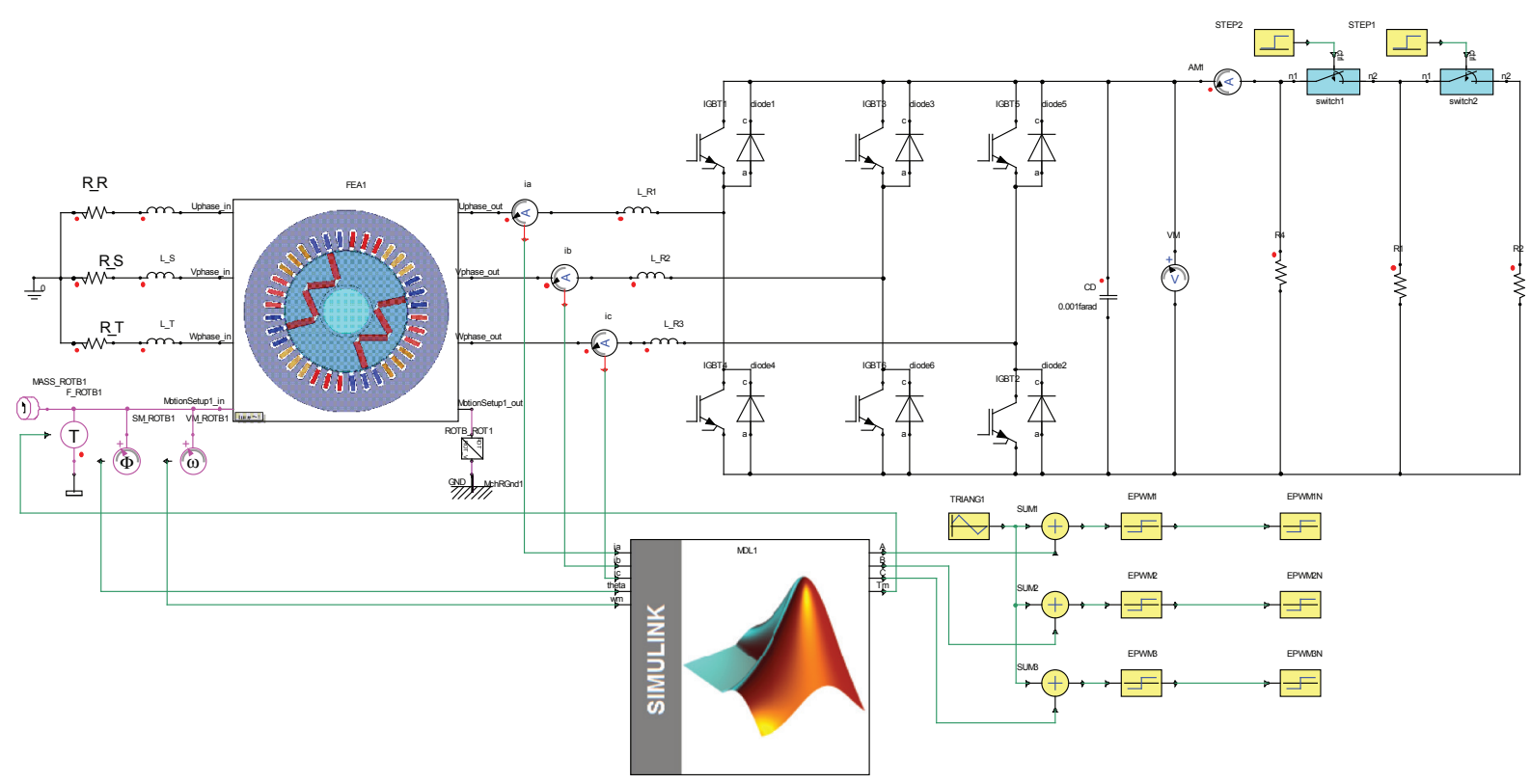

Fig. 4. Schematic diagram of the co-simulation setup implemented in Simplorer

In Fig. 4, the link to the FEA software (ANSYS Maxwell) is represented by the symbol with the image of the PMSG. Connections are the signals or variables shared between the software. Note that at the left side of this symbol, the resistors $R \_R, R \_S$, and $R \_T$ are the winding resistance of the machine (5.53 $\Omega$ each) and next to the them the end-winding leakage inductance $(4.53 \mathrm{mH})$. The Simulink control connection is shown as a block in the lower part. Observe that the switching signals for the transistors, i.e., sinusoidal pulse width modulation (SPWM), are generated in the SPICE software where the three-phase reference is compared with the triangular signal at $3 \mathrm{kHz}$ (lower right).

\subsection{Analyzed scenarios}

The magnetic flux density, $B$, distribution of the four analyzed scenarios, for the investigation of the control response, are presented in Fig. 5. For all scenarios, the input torque was kept constant at $15 \mathrm{Nm}$, and the reference speed was changed from the nominal $1500 \mathrm{rpm}$ initially to half speed (750 rpm) with a 1 second ramp (from $2.5 \mathrm{~s}$ to $3.5 \mathrm{~s}$ ). The first scenario is the healthy machine with all its Nd-Fe-B magnets (N38SH). The second scenario (Fig. 5b) is the PMSG with one magnet less (12.5\% less). The third scenario in Fig. $5 \mathrm{c}$ is the PMSG with $25 \%$ less magnets on the same side of the rotor. Finally, the fourth scenario is also with $25 \%$ less magnets (two magnets less) but on opposite sides of the rotor. Here is important to mention that although the $B-H$ curve was introduced in the FEA software for $20^{\circ} \mathrm{C}$, the software capabilities explained at the introduction, allow for the calculation of the $B-H$ curve at any temperature (constant $80^{\circ} \mathrm{C}$ in this article) and its operating point.

Previous analyzes in the literature, e.g., in (Kim et al. 2014) and in (Lee et al. 2014)) showed that for a strong armature reaction field, partial demagnetization occurs on the trailing edge of the pole, i.e., on the last magnet 
(or last part of the magnet) on the pole as seen from the rotor's rotation direction. Taking into account that the rotation of the machine is counterclockwise, the results from the literature would indicate that the more pragmatic analysis are the cases in Figures $5 b$ and $5 d$. Nevertheless, the case shown in Fig. $5 c$ is also interesting since as explained in the literature, the partial demagnetization could have been provoked by another failure mechanism like corrosion as explained in Gieras (2009). Here it is important to mention that the study of the failure mechanism that caused these scenarios is out of the scope of this article.
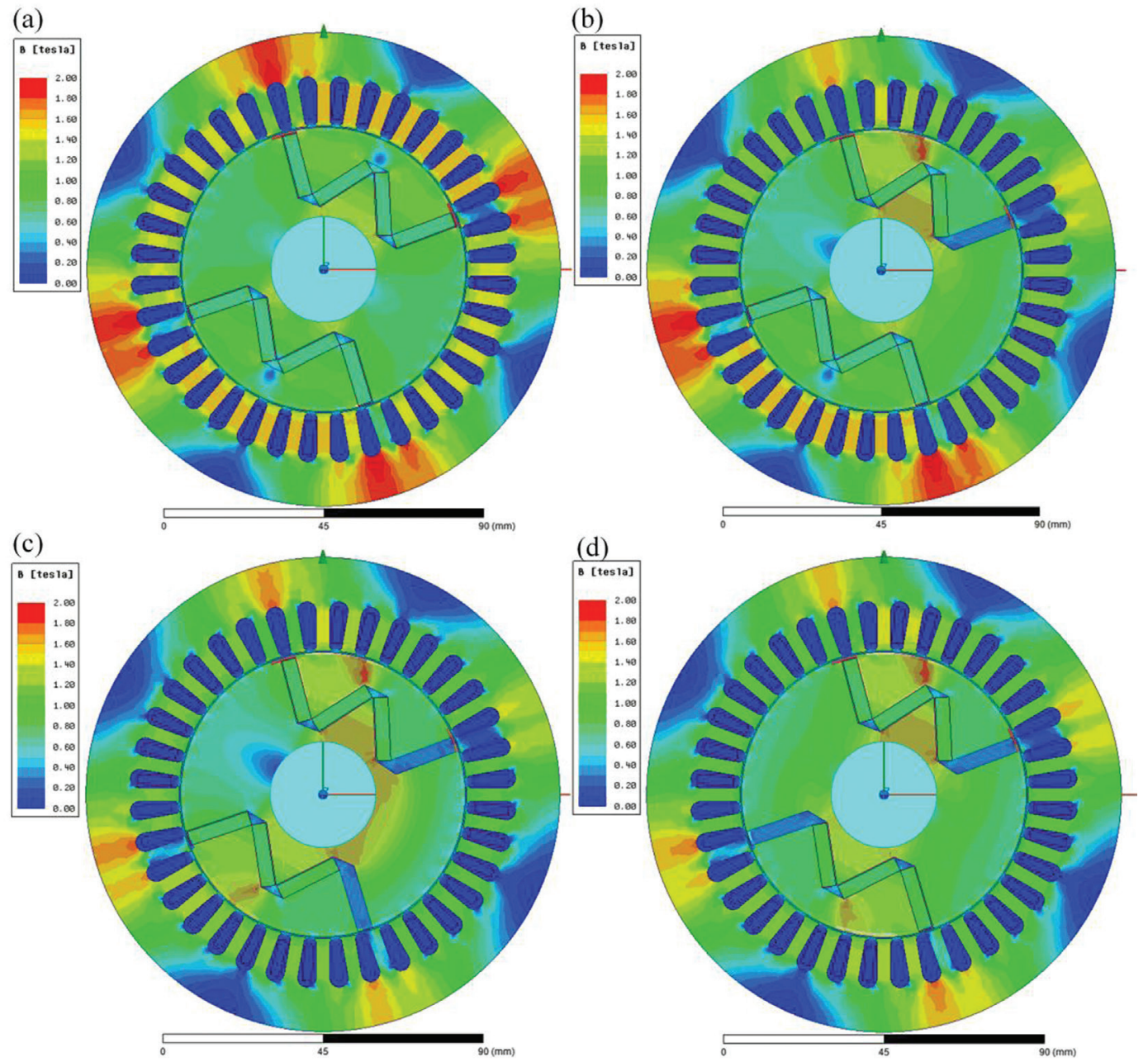

Fig. 5. Magnetic field density, $B$, distribution in open circuit (no load) for the four scenarios analyzed, healthy (a), $12.5 \%$ less magnet (b), $25 \%$ less two magnets (c), and $25 \%$ less two magnets opposite side (d)

\section{Analysis of the partially demagnetized PMSG under DFOC}

In Fig. 6, the results for the speed control for the four scenarios is presented. The initial transient (1 second) is not shown because the initial conditions for the co-simulation are not smooth (no reference ramp), also for clarity purposes the results are presented in two separate plots. The steady state of the control (1.5 s-2 s) has oscillations connected with the machine ripple torque and torque pulsations from the converter (phase current commutation). These torque ripple oscillations are also visible at half speed $(4.27 \mathrm{~s}-5 \mathrm{~s})$ but with less torque pulsations from the converter (steady state).

Notice in Fig. $6 \mathrm{~b}$ that the DFOC is able to bring the system to steady state even with two magnets less (25\% demagnetization), but the system response has big oscillations during the transient, e.g., the initial oscillations that finish after $1.5 \mathrm{~s}$ and change in the DC bus load at $2 \mathrm{~s}$. These oscillations are not as big when the PMSG is operating 
at lower speed (after $3.5 \mathrm{~s}$ ). The big oscillations are connected with the tuning of the proportional integral (PI) controller but note that in the healthy case, the oscillations are damped faster than in other cases, obviously tuning was made for the healthy case, and kept the same PI gains for all the experiments.

In Fig. 7, the power output (DC bus voltage times DC bus current) is compared. For clarity purposes, only the healthy machine and the two cases with two magnets less are shown. The one magnet less scenario falls in between the healthy and two magnets less curves. From Fig. 7 is important to note that both cases of two magnets less have almost the same behavior although for the two magnets opposite side (Fig. 5d) there is some low frequency

(a)

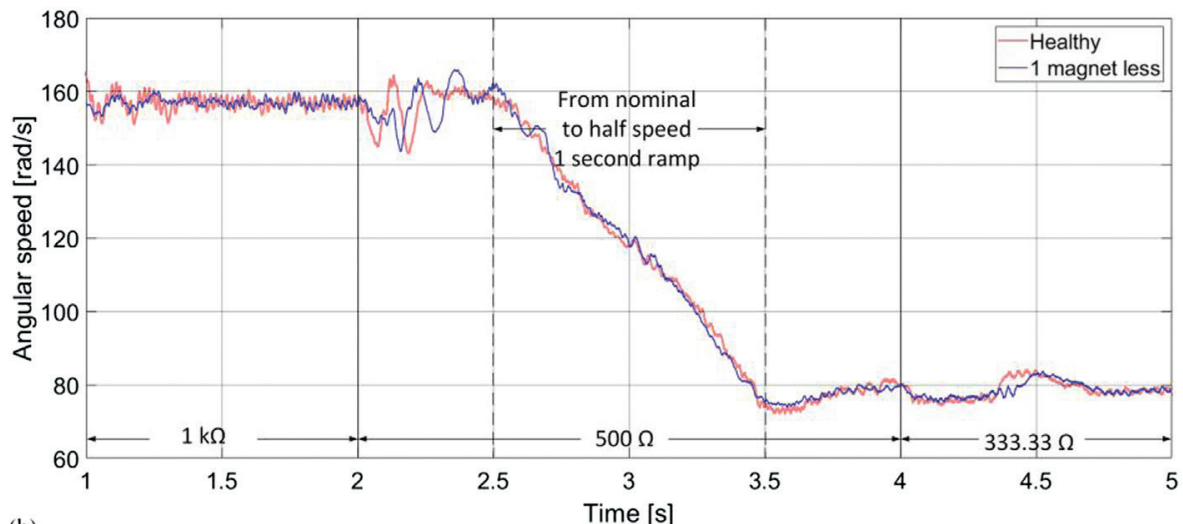

(b)

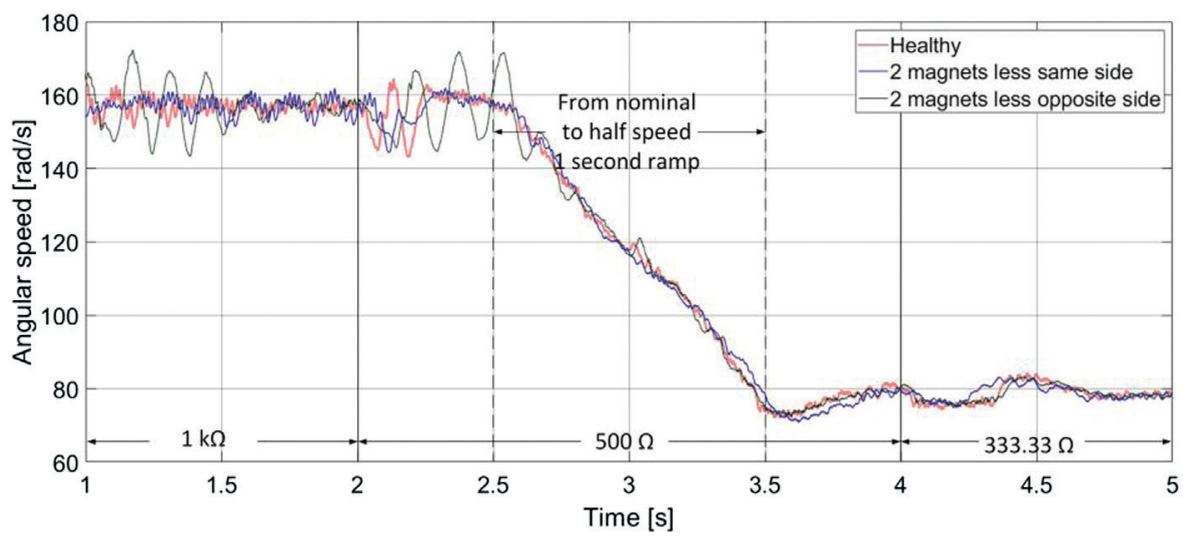

Fig. 6. Angular speed from nominal $1500 \mathrm{rpm}(157 \mathrm{rad} / \mathrm{s})$ to half speed $(78.5 \mathrm{rad} / \mathrm{s})$ comparison for healthy and one magnet less (a), and healthy and two magnets less (b)

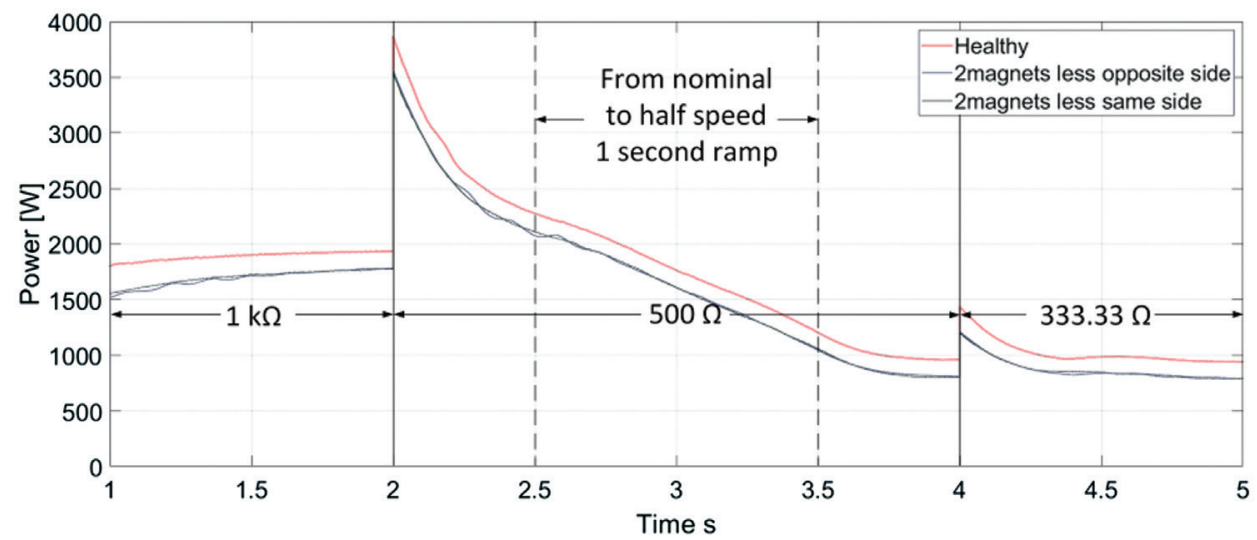

Fig. 7. Power output at the DC bus load 
ripple visible in the power output (around $2.5 \mathrm{~s}$ ). Also notice that the healthy machine was able to generate almost $2 \mathrm{~kW}$ of power with a $1 \mathrm{k} \Omega$ resistor and around $2.2 \mathrm{~kW}$ with nominal speed after transient (around $2.5 \mathrm{~s}$ ), when the resistance was changed to $500 \Omega$. Finally, the healthy PMSG generates about $1 \mathrm{~kW}$ with a $333.33 \Omega$ DC bus resistance. Here it is important to remind that all the co-simulations where run with a $15 \mathrm{Nm}$ input torque and the time step was $50 \mu \mathrm{s}$.

In Fig. 8, the phase currents of the healthy machine are shown, note that the shape of the currents due to the $3 \mathrm{kHz}$ SPWM. Also, notice the change in frequency between the signals in the inset (lower side) of Figure 8 . The left one is at nominal speed and right one is at half speed, but both have the same amplitude because the input torque is kept constant $(15 \mathrm{Nm})$.

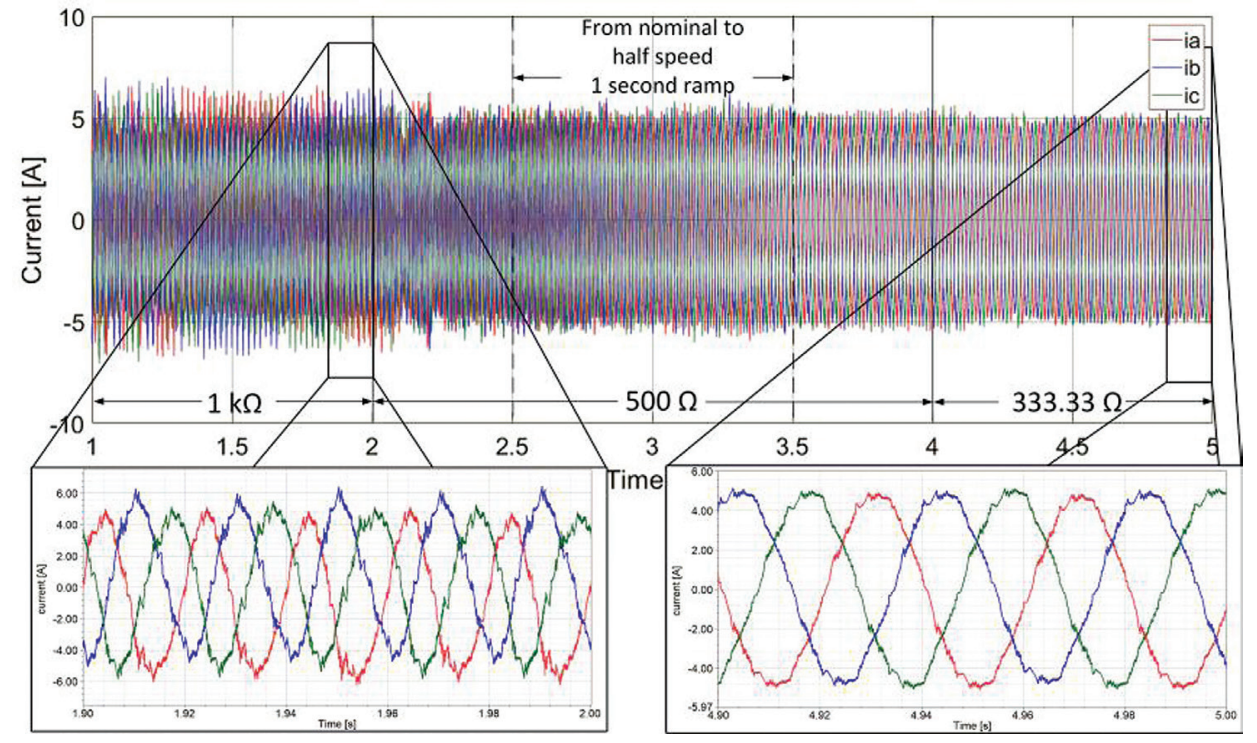

Fig. 8. Phase currents for the healthy machine

As mentioned in the introduction, this co-simulation approach allows for the or analysis purposes the DQ currents are compared in Fig. 9. Previous literature, e.g., in (Casadei et al. 2012) have shown analytically that the oscillations in the D-axis current can be used to detect demagnetization, even under nonstationary conditions. Also in Hong et al. (2012), the authors use D-axis current in their detection method validated experimentally.

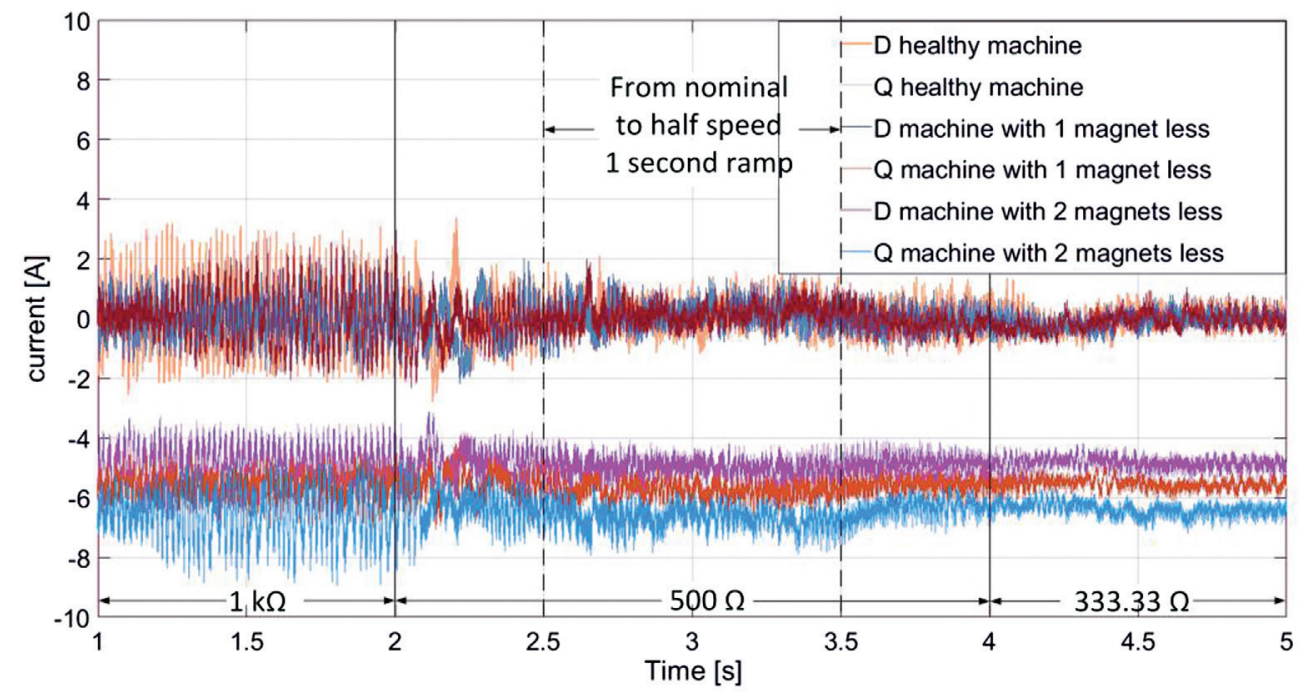

Fig. 9. DQ current signals comparison 
From Fig. 9, it can be seen that the D-axis currents have very big ripples when the PMSG is loaded (1 k $\Omega)$ and its operating at nominal speed. On the other hand, when the PMSG is operating with a load of $333.33 \Omega$ and at half speed $(750 \mathrm{rpm})$ the ripples are smaller. Here it is important to mention that the difference between the Q-axis currents is because the input torque was the same for all co-simulations, which means that the control has to compensate for the absence of magnets to maintain the reference speed. Obviously, without exact knowledge of the input torque (which is difficult to measure), the $Q$ signal level is unsuitable for detecting demagnetization.

In Fig. 10, the DQ signals are compared for both scenarios with two magnets less. Notice that the ripple connected with the speed signal (Fig. 6b) is also visible in the D-axis signal of the scenario without opposite side magnets. To analyze the D current signal, a well-known method used in vibration analysis of rotating machinery is proposed. Envelope spectrum allows the analysis of signals with low-frequency repetitive features like the Ball Pass Frequency in ball bearings (Randall, 2011).

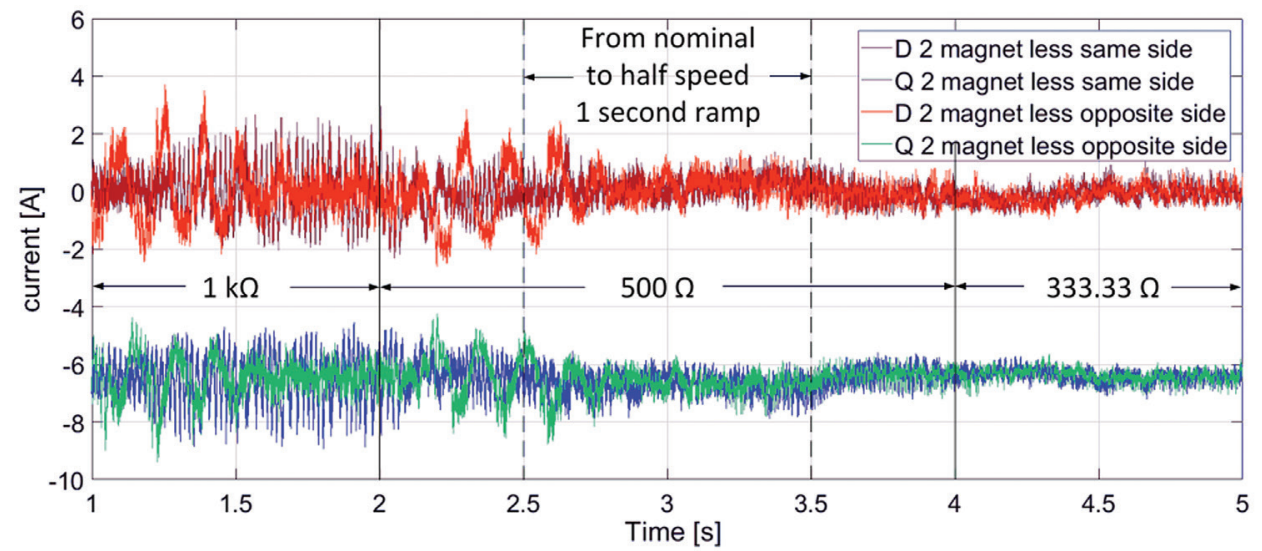

Fig. 10. $D Q$ current signals comparison depending on demagnetization position

Finally, for comparison purposes the power spectrum of $D$ current signals are presented in Fig. 15; and it is clear that for such short time of sampled signals $(500 \mathrm{~ms})$, the envelope spectrum approach shows better results in differentiating frequency peaks even when Fig. 15 has a $6 \mathrm{~Hz}$ resolution, i.e., two peaks can be separated from each other if they are $6 \mathrm{~Hz}$ apart.

From the results shown in Figures 11, 12, 13, and 14, some conclusions can be done: even in the spectrum of Fig. 11, the difference between the healthy machine and the partially demagnetized cases are clear, namely the healthy machine shows a higher peak amplitude. Here it is important to notice that the Fig. 11 shows an obvious nonstationary signal, since the load change transients and the reference speed ramp. From Figures 12 and 13 , it
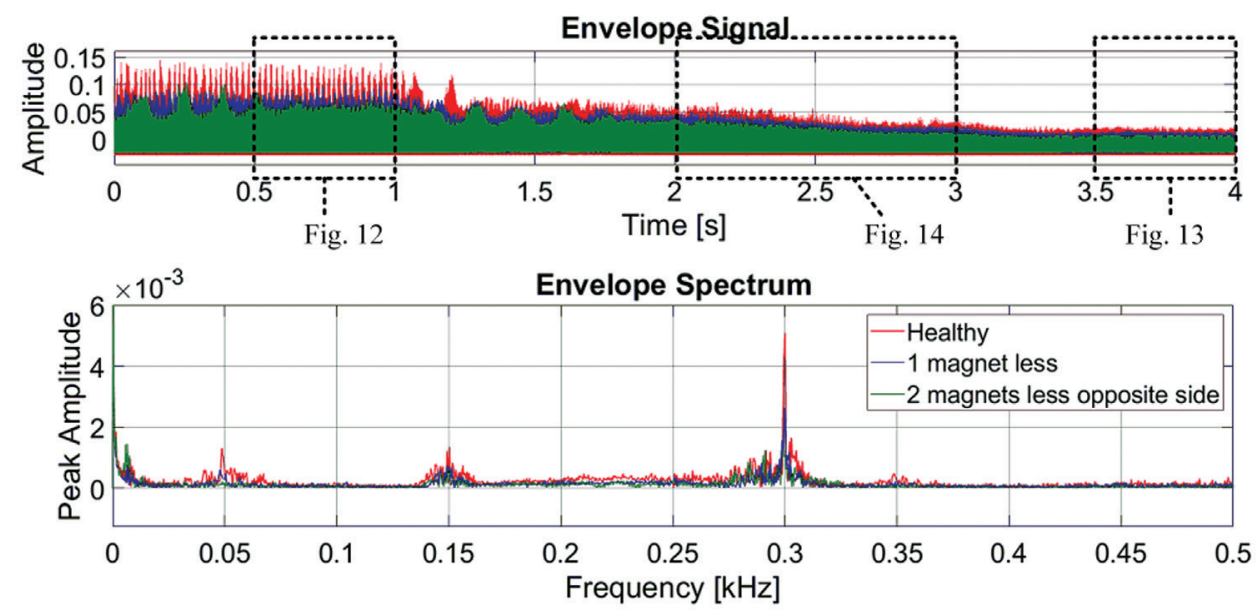

Fig. 11. D current signal's envelope and envelope spectrum comparison 
is more apparent that the spectrum of steady-state signal conditions make the peaks narrower, which means they can be better resolved. For better frequency resolution, the steady-state samples should be taken over a longer period of time (often $10 \mathrm{~s}$ in MCSA), but an advantage of the proposed approach is that they show good frequency resolution even with only $500 \mathrm{~ms}$ as in Figures 12 and 13 . Notice that even in a nonstationary condition as the reference change (speed ramp) in Fig. 14, the amplitude of the peaks show a clear difference between healthy
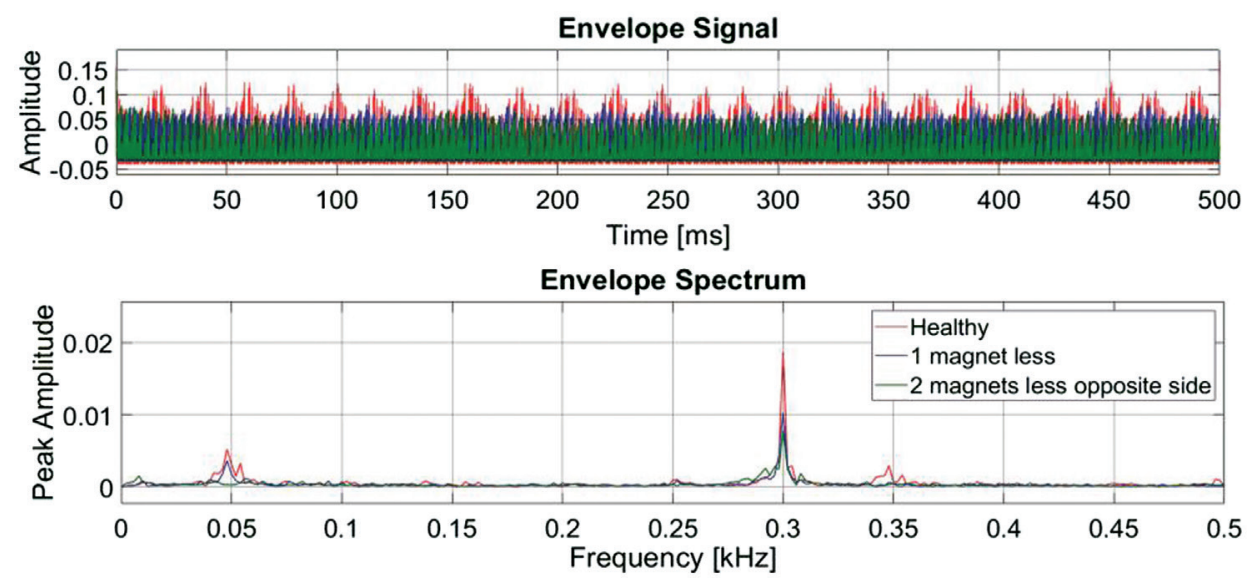

Fig. 12. $D$ current signal's envelope and envelope spectrum comparison at steady-state nominal speed
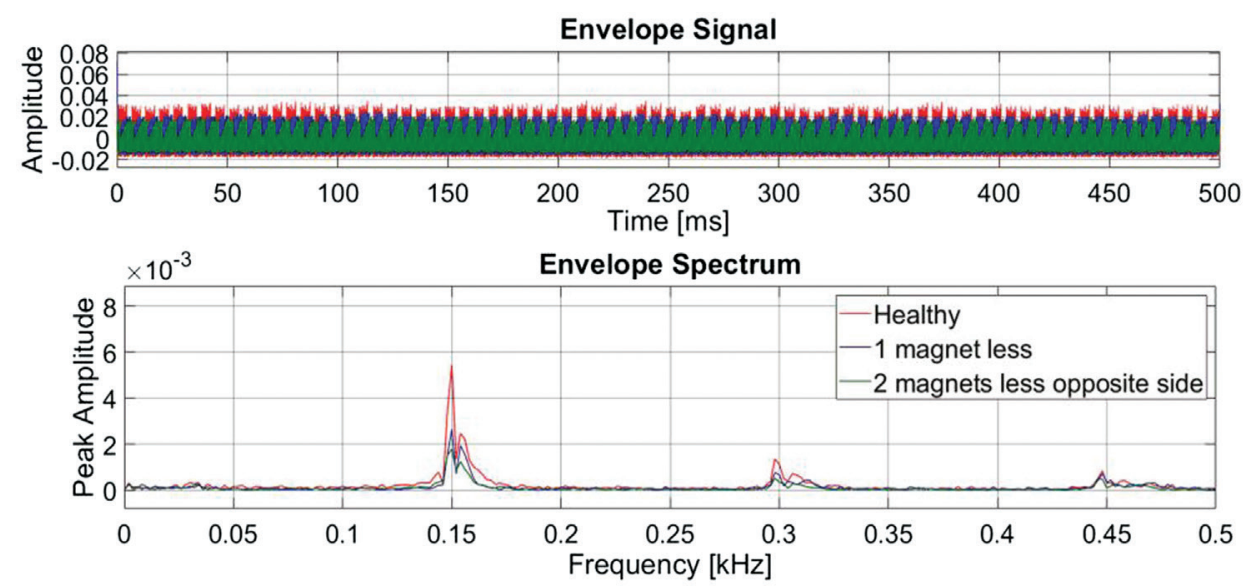

Fig. 13. D current signal's envelope and envelope spectrum comparison at steady-state half speed
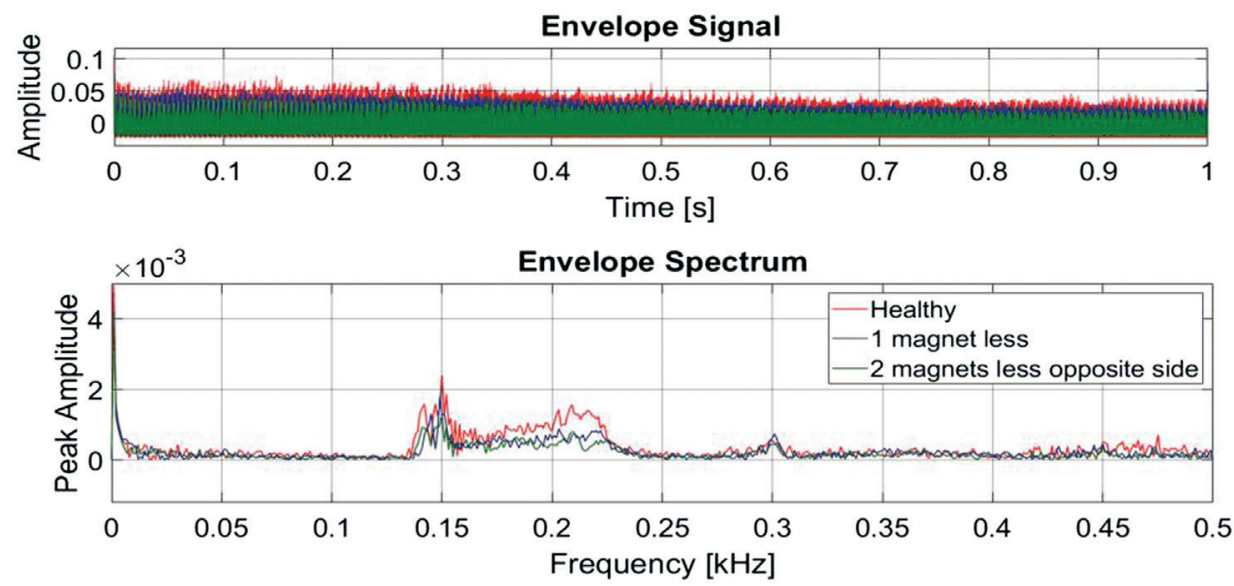

Fig. 14. D current signal's envelope and envelope spectrum comparison during speed ramp 


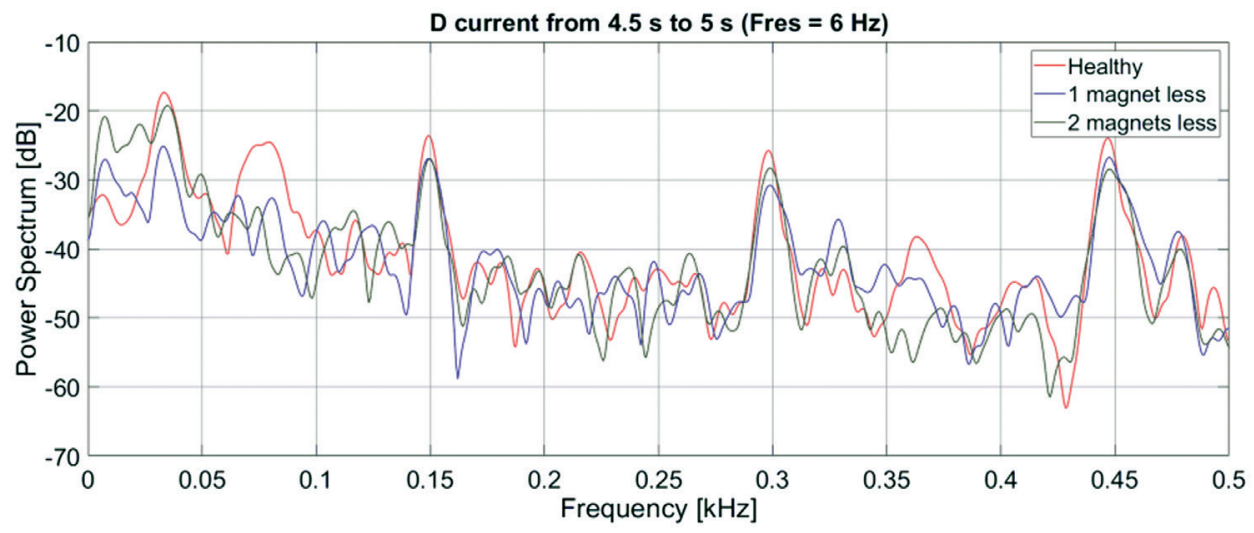

Fig. 15. FFT of D current signals comparison during steady-state half speed

and demagnetized machine. As it was demonstrated in the literature (Le Roux et al., 2007), the demagnetization faults are connected with the mechanical rotational frequency (i.e., multiples of rotational frequency), which is the electrical frequency divided by the number of pole pairs (two in this case). Therefore, looking at the tallest peak in Fig. 12 located in $300 \mathrm{~Hz}$, which is 12 times the rotational frequency at nominal speed (25 Hz), and the peak in Fig. 13 at $150 \mathrm{~Hz}$ at half the nominal speed is consequent with those findings.

\section{Conclusions}

From the analysis shown in Section 3, two main conclusions can be done: first, the continuous operation of the PMSG after partial demagnetization is possible; second, that the partial demagnetization can be detected and assessed from the electrical feedback signals, i.e., DQ currents (demagnetization diagnostics). Of course, these conclusions have some provisions, e.g., the first one assumes that the current PI controllers of the DFOC do not go into saturation without the magnetic material (percentage of demagnetization), also, as shown in Fig. 6b, the dynamic response of the system is altered, therefore the controller tuning should be chosen to allow some flexibility (oscillations) when the machine loses magnetic material.

About the second conclusion, it is important to state that previous literature have already demonstrated the possibility to detect and assess partial demagnetization from electrical feedback signals, but the approach was different, e.g., in Ruiz et al. (2010) with MCSA and HHT. In this article, the combination of a new method for simulating this kind of faults, namely co-simulation, and the analysis of the reference frame $D Q$ signals is performed. It was demonstrated that a classical method from the mechanical vibration analysis, namely envelope spectrum, bring good results in detecting and assessing the level of demagnetization. As with most of the previous literature, an a priori knowledge of the base-line signals is much necessary, i.e., the amplitude of the healthy machine harmonics.

The possibility of detecting demagnetization from the DQ signals was proposed in theory by an analytical model in (Casadei et al. 2012), although the analysis of DQ signals in IM's fault detection was proposed earlier (Cusido et al., 2006), even there for IM is stated that the fault harmonics and signal noise make the detection difficult. Here the envelope spectrum helps to this matter.

Further work will include the analysis of experimental measurements where the correct acquisition of the rotor's position angle plays a very important role for this purpose.

\section{Acknowledgments}

Quintal-Palomo thanks the funding from the Mexican Council of Science and Technology CONACYT and the Department of Research, Innovation and Higher Education of the Yucatan State SIIES grant number 312140. 


\section{References}

Baranski, M., Szelag, W. and Jedryczka, C. (2017). Influence of Temperature on Partial Demagnetization of the Permanent Magnets During Starting Process of Line Start Permanent Magnet Synchronous Motor. In: 2017 International Symposium on Electrical Machines (SME), Naleczow, Poland, 18-21 June 2017, IEEE, pp. 1-6.

Casadei, D., Filippetti, F., Mengoni, M., Gritli, Y., Serra, G., Tani, A. and Zarri, L. (2012). Detection of Magnet Demagnetization in Five-Phase Surface-Mounted Permanent Magnet Generators. In: 2012 3rd IEEE International Symposium on Power Electronics for Distributed Generation Systems (PEDG), Aalborg, Denmark, 25-28 June 2012, IEEE, pp. 841-848.

Cusido, J., Rosero, J. A., Ortega, J. A., Garcia, A. and Romeral, L. (2006). Induction Motor Fault Detection by Using Wavelet Decomposition on dq0 Components. IEEE International Symposium on Industrial Electronics, 3, pp. 2406-2411.

Fei, W., Luk, P. C. K., Ma, J., Shen, J. X. and Yang, G. (2009). A high-Performance Line-Start Permanent Magnet Synchronous Motor Amended from A Small Industrial Three-Phase Induction Motor. IEEE Transactions on Magnetics, 45(10), pp. 4724-4727.

Gieras, J. (2009). Permanent Magnet Motor Technology, 3rd ed., J. F. Gieras, ed., CRC Press, doi:10.1201/9781420064414.

Hong, J., Park, S., Hyun, D., Kang, T. J., Lee, S. B., Kral, C. and Haumer, A. (2012). Detection and Classification of Rotor Demagnetization and Eccentricity Faults for PM Synchronous Motors. IEEE Transactions on Industry Applications, IEEE, 48(3), pp. 923-932.

Kang, G.-H., Hong, J.-P., Kim, G.-T. and Park, J.-W. (2000). Improved Parameter Modeling of Interior Permanent Magnet Synchronous Motor Based on Finite Element Analysis. IEEE Transactions on Magnetics, 36(4), pp. 1867-1870.

Kim, K. T., Lee, Y. S. and Hur, J. (2014). Transient Analysis of Irreversible Demagnetization of Permanent-Magnet Brushless DC Motor with Interturn Fault Under the Operating State. IEEE Transactions on Industry Applications, IEEE, 50(5), pp. 3357-3364.

Lee, Y.-S., Kim, K.-T. and Hur, J. (2014). Finite-Element Analysis of the Demagnetization of IPM-Type BLDC Motor with Stator Turn Fault. IEEE Transactions on Magnetics, 50(2), pp. 889-892.
Le Roux, W., Harley, R. G. and Habetler, T. G. (2003). Detecting Rotor Faults in Permanent Magnet Synchronous Machines. IEEE International Symposium on Diagnostics for Electric Machines, Power Electronics and Drives, SDEMPED 2003 Proceedings, 22(1), pp. 198-203.

Le Roux, W., Harley, R. G. and Habetler, T. G. (2007). Detecting Rotor Faults in Low Power Permanent Magnet Synchronous Machines. IEEE Transactions on Power Electronics, 22(1), pp. 322-328.

Moon, S., Jeong, H., Lee, H. and Kim, S. W. (2017). Detection and Classification of Demagnetization and Interturn Short Faults of IPMSMs. IEEE Transactions on Industrial Electronics, 64(12), pp. 9433-9441.

Park, Y., Fernandez, D., Lee, S. B., Hyun, D., Jeong, M., Kommuri, S. K., Cho, C., Reigosa, D. D. and Briz, F. (2019). Online Detection of Rotor Eccentricity and Demagnetization Faults in PMSMs Based on Hall-Effect Field Sensor Measurements. IEEE Transactions on Industry Applications, 55(3), pp. 2499-2509.

Pramanik, A., Baka, S., Dambhare, S. S., Ugale, R. T. and Chaudhari, B. N. (2014). Induced Pole Rotor Structure for Line Start Permanent Magnet Synchronous Motors. IET Electric Power Applications, 8(4), pp. 131-140.

Quintal-Palomo, R. E., Gwozdziewicz, M. and Dybkowski, M. (2017). Design and Test of an Internal Permanent Magnet Generator for Small Wind Turbine Applications. In: 2017 19th European Conference on Power Electronics and Applications (EPE'17 ECCE Europe), Warsaw, Poland, 11-14 September 2017, IEEE, pp. P.1-P.4.

Randall, R. B. (2011). Vibration-Based Condition Monitoring, Vibration-Based Condition Monitoring: Industrial, Aerospace and Automotive Applications. Chichester, UK: John Wiley \& Sons, Ltd, doi:10.1002/9780470977668.

Rosu, M., Saitz, J. and Arkkio, A. (2005). Hysteresis Model for Finite-Element Analysis of PermanentMagnet Demagnetization in A Large Synchronous Motor Under A Fault Condition. IEEE Transactions on Magnetics, 41(6), pp. 2118-2123.

Ruiz, J. R. R., Garcia Espinosa, A., Romeral, L. and Cusidó, J. (2010). Demagnetization Diagnosis in Permanent Magnet Synchronous Motors Under Non-Stationary Speed Conditions. Electric Power Systems Research, 80(10), pp. 1277-1285. 
Ruoho, S., Dlala, E. and Arkkio, A. (2007). Comparison of Demagnetization Models for Finite-Element Analysis of Permanent-Magnet Synchronous Machines. IEEE Transactions on Magnetics, 43(11), pp. 3964-3968.

Wang, C., Delgado Prieto, M., Romeral, L., Chen, Z., Blaabjerg, F. and Liu, X. (2016). Detection of Partial Demagnetization Fault in PMSMs Operating under Nonstationary Conditions. IEEE Transactions on Magnetics, IEEE, 52(7), pp. 1-4.

Whaley, D. M. M., Soong, W. L. L. and Ertugrul, N. (2005). Investigation of Switched-Mode Rectifier for Control of Small-Scale Wind Turbines. Fourtieth IAS Annual Meeting. Conference Record of the 2005 Industry Applications Conference, 2005, IEEE, 4(4), pp. 2849-2856.

Yang, W. (2013). Condition Monitoring the Drive Train of a Direct Drive Permanent Magnet Wind Turbine Using Generator Electrical Signals. Journal of Solar Energy Engineering, 136(2), p. 021008.
Yang, Z., Shi, X. and Krishnamurthy, M. (2014). Vibration monitoring of PM synchronous machine with partial demagnetization and inter-turn short circuit faults. In: 2014 IEEE Transportation Electrification Conference and Expo (ITEC), Dearborn, MI, USA, 15-18 June 2014, IEEE, pp. 1-6.

Zawilak, T., Antal, L. and Zawilak, J. (2006). Wpływ obciążenia na odkształcenie prądu w silniku. Maszyny Elektryczne - Zeszyty Problemowe, 75, pp. 1-4.

Zhou, P., Lin, D., Fu, W. N., Ionescu, B. and Cendes, Z. J. (2006). A General Cosimulation Approach for Coupled Field-Circuit Problems. IEEE Transactions on Magnetics, 42(4), pp. 1051-1054.

Zhou, P., Lin, D., Xiao, Y., Lambert, N. and Rahman, M. A. (2012). Temperature-Dependent Demagnetization Model of Permanent Magnets for Finite Element Analysis. IEEE Transactions on Magnetics, 48(2), pp. 1031-1034. 